Revista de la red interuniversitaria de estudios sobre las literaturas rioplatenses contemporáneas en Francia

$18 \mid 2018$

El río y la ciudad

\title{
Ciudad y paisaje
}

\section{Michel Collot}

Traductor: Ricardo Torre, Université Paris Est-Créteil y IMAGER

\section{(2) OpenEdition}

\section{Journals}

Edición electrónica

URL: http://journals.openedition.org/lirico/4568

DOI: $10.4000 /$ lirico.4568

ISSN: 2262-8339

Editor

Réseau interuniversitaire d'étude des littératures contemporaines du Río de la Plata

Referencia electrónica

Michel Collot, « Ciudad y paisaje », Cuadernos LIRICO [En línea], 18 | 2018, Puesto en línea el 16 septiembre 2018, consultado el 03 mayo 2019. URL : http://journals.openedition.org/lirico/4568 ; DOI : $10.4000 /$ lirico.4568

Este documento fue generado automáticamente el 3 mayo 2019.

\section{cc) (i) $\odot$}

Cuadernos LIRICO está distribuido bajo una Licencia Creative Commons Atribución-NoComercial-

SinDerivar 4.0 Internacional. 


\section{Ciudad y paisaje}

\section{Michel Collot}

Tradución : Ricardo Torre, Université Paris Est-Créteil y IMAGER

\section{NOTA DEL EDITOR}

En nombre de Cuadernos LIRICO agradecemos al autor la autorización para publicar esta traducción. Procedencia: "Ville et paysage", La Pensée-paysage. Philosophie, arts, littérature, París, Actes Sud / ENSP, 2011, p. 69-78. Las cursivas son siempre del autor. La traducción de las citas entre comillas siempre es del traductor. Las notas y comentarios del traductor irán entre corchetes.

1 No hay motivo para reservar la noción de paisaje a los espacios naturales o al medio rural, como nos induce a hacerlo cierta tradición artística y literaria, ya sea la poesía bucólica apegada al locus amoenus, la pintura clásica que erige como modelo el campo romano, la estética de lo sublime que se enfrenta a la desmesura de la alta montaña, o la exaltación del wilderness en la cultura norteamericana. La pintura mural Efectos del buen gobierno, considerada a menudo la primera representación paisajística en la historia de la pintura europea, brinda un panorama de la región de Siena que incluye la ciudad en medio de los campos que la rodean ${ }^{1}$.

2 Lo que cuenta es menos el tipo de espacio, natural o cultivado, rural o urbano, que la mirada puesta en el mismo: la ciudad se vuelve paisaje en cuanto un sujeto la percibe como un elemento inserto en su entorno y que forma con él un conjunto cuya coherencia sensible produce sentido. Ahora bien, esta percepción es hoy a menudo difícil de captar por varios factores: la extensión de las megalópolis contemporáneas, esas endless cities cuyo centro está en todos lados y su circunferencia en ninguna parte, y cuyos límites se diluyen en provecho de una periurbanización, e incluso de una rururbanización generalizada. En el seno de este tejido urbano indiferenciado, el habitante de la ciudad a veces se siente perdido, por falta de puntos de referencia.

3 A partir de ahí, una de las tareas que debe realizar el urbanismo contemporáneo es volver a dar a la ciudad una forma y un contorno que permitan reconstruir un verdadero 
"paisaje urbano". Es significativo el esta expresión haya aparecido en nuestra lengua en el momento en que la ciudad moderna comenzaba a desarrollarse más allá de sus límites tradicionales y se convertía en el lugar vital de una proporción creciente de la población, que hoy aún más que antes necesita poder reconocerse en un entorno urbano o suburbano, destino actual de casi todo el mundo.

El paisaje no es solo un modelo para las artes y el pensamiento; es también y primeramente un entorno vital. La cuestión de los "paisajes comunes y corrientes", los de la vida cotidiana, de nuestras ciudades y suburbios, últimamente ha llegado a ocupar el primer lugar en la reflexión y la acción públicas. No hay que oponerla a sus expresiones literarias y artísticas, pues estas nos ayudan a tomar conciencia de los valores y desafíos ligados a todo paisaje, ya sea trivial o "extraordinario". Y recíprocamente, a veces es la experiencia que tenemos con espacios difíciles lo que nos hace receptivos a las artes del paisaje.

5 Si soy particularmente sensible a estas, se debe quizás a que viví durante una gran parte de mi infancia y adolescencia en La Courneuve ${ }^{2}$, muy cerca de la famosa Cité de los $4000^{3}$. Diariamente me confronté a los desaciertos de un urbanismo que, para responder a necesidades masivas de vivienda y a imperativos económicos y tecnocráticos, sacrificó los elementos y los equilibrios constitutivos de un verdadero paisaje urbano. En este entorno sentí un profundo malestar, que venía de la negación de lo que podía configurar por lo demás mi relación viva con el paisaje, que tenía la suerte de conocer durante las vacaciones pasadas en casa de mis abuelos, en el campo champañés ${ }^{4} \mathrm{o}$ en una pequeña ciudad del Vaucluse 5 .

6 Las dificultades que afectan a las "cités" tienen por supuesto primero causas sociales, pero en mi opinión estas se ven agravadas por la manera como se ha planificado el espacio brindado a quienes viven en estos barrios o los frecuentan. La dialéctica de lo visible y de lo invisible rige no solo nuestra percepción del paisaje, sino también nuestras relaciones con los demás; atañe a la relación entre el espacio público y el privado, entre lo individual y lo colectivo. El equilibrio entre lo que se muestra y lo que se oculta preserva a la vez la intimidad y la socialidad: le permite al sujeto ver sin ser visto desde todos los lugares; pero, impidiéndole ver todo, lo obliga a recurrir al punto de vista del otro. Sin embargo esta estructura del horizonte a menudo se malogra en el espacio de las cités.

7 Sentía agorafobia al cruzar la de los 4000, especialmente cuando tenía frente a mí un bloque de unos cien metros de largo y unos veinte pisos, que fue destruido hace algunos años. Este edificio bloqueaba por completo mi perspectiva, obligándome a hacer un largo recorrido para encontrar una vista que me liberara de una especie de opresión visual. Asimismo, la fachada se presentaba como una pared totalmente lisa, sobre la cual se deslizaba la mirada sin poder asirse de agarre alguno: una entrada, un saliente, un juego de luces y sombras. De esta fachada que me tapaba por completo la vista, todo se presentaba de manera uniforme, exhibido, comenzando por las ventanas, multiplicadas de forma idéntica un vertiginoso número de veces. Ahora bien, como el terreno en el que se había construido el edificio era perfectamente plano y totalmente desprovisto de todo muro vegetal o de otro tipo, me hallaba a la vez privado de horizonte y expuesto virtualmente a la vista de esas innumerables ventanas. Se habían reunido las condiciones para que la mirada y la presencia del otro pudieran vivirse como agresivas.

8 En tal espacio, al individuo le cuesta encontrar su lugar y el punto de vista que le permitiría apropiárselo. Los arquitectos modernos a menudo han pasado por alto el punto de vista de los habitantes, en todos los sentidos del término. En el campus de Nanterre ${ }^{6}$, 
maravilla de la arquitectura lineal de los años 1960, se construyó, en los años 1990, un nuevo edificio destinado a dar un poco de espacio a los treinta y seis mil estudiantes que se amontonaban en locales previstos para acoger a doce mil. Para integrar mejor el nuevo edificio al contexto, el arquitecto simplemente lo unió a uno de los que ya existían, el D, cegando así por completo una de sus fachadas. El personal y los estudiantes que realizan sus actividades en ambientes privados en adelante de luz y de horizonte hubieran apreciado que el arquitecto integrara a sus planos el punto de vista de ellos. Se vengaron simbólicamente: al nuevo edificio, denominado oficialmente DD, ellos lo bautizaron "de prima" (D') ${ }^{7}$.

9 Este urbanismo prácticamente no respeta tampoco el equilibrio entre vacío y lleno que es central en la reflexión china sobre el paisaje ${ }^{8}$, y que configura la vida de una ciudad. A la densificación masiva del tejido urbano los planificadores creyeron poder subsanarla creando "espacios verdes" de baja densidad. Pero demasiado a menudo, estas reservas de vacío son expulsadas hacia la periferia de los núcleos densos y no se articulan bien con estos. $O$ bien se los diseña y decide en el plano o en el mapa sin tener en cuenta su inscripción en el espacio sensible. Si miramos el plano de una "cité", podríamos creer que los espacios vacíos superan el espacio construido. Pero basta con ir al lugar en cuestión para ver que la relación está invertida en el ámbito de la percepción. La escasa superficie ocupada por los edificios se compensa por la altura de estas construcciones, y es esta última la que cuenta para quien camina en la cité a través de los espacios vacantes que en la mayoría de los casos son solo terrenos baldíos, y dejan que la mirada choque perpetuamente contra las paredes de hormigón que los encierran. Así se yuxtaponen, sin articularse, espacios llenos sin falla, totalmente asfixiantes, y vacíos vertiginosos porque no se articulan de forma estructural con las construcciones. Si se mira al contrario el plano de un barrio tradicional, podría creerse que los llenos superan a los vacíos. Pero estos vacíos, inferiores cuantitativamente hablando, son vacíos vivos, que penetran lo lleno del tejido urbano para irrigarlo y animarlo. Y cuando uno está en la calle, tiene delante una perspectiva que puede ser acotada, pero que es cambiante, gracias a un intercambio renovado constantemente entre lo lleno de las fachadas y los vacíos de la calle, de las plazas y de los patios.

10 Los vacíos planificados en las construcciones urbanas son lugares en donde estas pueden entrar en contacto con la naturaleza, de cuyo alejamiento sufren hoy tantos habitantes de la ciudad; los espacios abiertos que dejan penetrar el cielo, la luz, lo vegetal o el agua en el centro mismo de la ciudad les permiten recobrar el contacto con los elementos naturales. Tales aberturas responden también a esta necesidad de un "desmesurable" cuya importancia vital se ha encargado de demostrar Bernard Lassus ${ }^{9}$. Acondicionar un lugar es conformarlo a la medida de sus habitantes, pero también ofrecerles ese margen de inconmensurable, que les impida ser prisioneros de su territorio. Es satisfacer también esa necesidad de trascendencia, a la que las religiones ya no siempre logran responder o a la que responden volviendo a introducir una lógica de clausura y exclusión; una trascendencia que ya no sería vertical, sino propuesta a ras de tierra, una trascendencia horizontal. El horizonte siempre reserva la posibilidad de un punto de vista nuevo sobre el mundo, que, por más que sea conocido, sigue abierto a percepciones y emociones nuevas. Y el retroceso indefinido del horizonte hace que nunca hayamos dado la vuelta al mundo porque es inconmensurable.

11 En la planificación de los paisajes urbanos, hay que prestar entonces la máxima atención a la interacción de todos los elementos que los componen, tanto naturales como humanos. 
Los edificadores de "conjuntos de bloques de viviendas" 10 a menudo los han concebido como entidades espaciales y sociales autónomas, pasando por alto las relaciones que deberían unirlos al resto del tejido urbano y suburbano, convirtiéndolos a veces en guetos. Paradójicamente les faltó la visión de conjunto que únicamente puede transformar la ciudad en un paisaje. Para lograr este objetivo, hay que sustituir una razón analítica, que durante demasiado tiempo ha tratado por separado los múltiples problemas que interfieren en la producción del espacio urbano, por una razón sintética, que los vincule y los piense realmente juntos. Esto supone renunciar a la práctica de la tabla rasa, y tener en cuenta el contexto arquitectónico, social, cultural, y natural en el que se inserta toda nueva instalación o edificio.

Desde hace tres décadas, se han multiplicado las tentativas para reevaluar y rehabilitar la relación que une las construcciones humanas con el "genio del lugar"11. Una de ellas es especialmente el sentido de la reflexión iniciada por Christian Norberg-Schulz, para quien la arquitectura es "un arte del lugar". Relaciona la "pérdida del lugar", que afecta a las sociedades modernas, con "la partición de la unidad del mundo de la vida entre sujeto y objeto" 12 , y halla en la fenomenología y el pensamiento heideggeriano la confirmación de que "la identidad del hombre está estrechamente ligada a la del lugar"13.

Como reacción contra una arquitectura "fuera del suelo", que aísla las construcciones de su contexto, numerosas realizaciones recientes dependen de una "arquitectura situada", que reinventa, gracias a las técnicas modernas, la alianza milenaria entre las construcciones y el paisaje. Estas arquitecturas "que se armonizan o dialogan con la línea del horizonte" evidencian, según Aaron Betsky, un nuevo método: "En lugar de aprehender las obras arquitectónicas como objetos desligados formalmente de la tierra, los arquitectos comienzan a considerarlas parte del paisaje y empiezan a ver el conjunto como un todo indivisible" ${ }^{14}$. Una expresión radical de esta fusión con el paisaje es la moda de los "rascatierra"; por oposición a los rascacielos, que proclaman muy alto la autonomía de las construcciones modernas, esos inmuebles, edificados al ras del suelo o incluso más o menos enterrados, "se conforman a la topografía de la tierra y solo la modifican con el fin de hacerla más explícita"15.

14 Esta inquietud por la integración al paisaje puede extenderse a escala de la ciudad entera. Anima por ejemplo algunos de los proyectos urbanísticos suscitados por la reciente consulta internacional sobre el porvenir de la metrópoli parisina ${ }^{16}$. El pliego de condiciones impuesto a los arquitectos hacía hincapié en la necesidad de conciliar el auge de la aglomeración con el respeto de las normas ecológicas fijadas por el Protocolo de Kioto. Varios proyectos intentaban dar consistencia a la idea de una "ciudad-naturaleza", y en este intento de reconciliar la cité con su entorno, a menudo es el paisaje, interfaz entre naturaleza y cultura, el que desempeña el papel de intermediario.

La extensión misma de la megalópolis parisina lleva a considerar su despliegue futuro a escala de lo que se denomina "el gran paisaje", por ejemplo siguiendo el eje natural constituido por el valle del Sena ${ }^{17}$ o eligiendo como puntos de referencia tales eminencias o confluencias ${ }^{18}$. El urbanismo contemporáneo recupera así los límites y los recursos de la topografía, que han dirigido a lo largo de la historia el establecimiento de los seres humanos: frente "al fracaso de la planificación erradicadora de la geografía [...] deseamos volver a basarnos en este dato fundamental: la geografía" ${ }^{19}$, dice Roland Castro.

Este aprovechamiento del marco geográfico inscribe el desarrollo urbano en la continuidad de los espacios y procesos naturales: "El gran paisaje convoca los grandes horizontes, conformados conjuntamente por los ciclos naturales y la actividad humana, 
en el centro de la metrópoli" ${ }^{20}$. Este contacto con la naturaleza no debería limitarse a los confines de la aglomeración, debe inmiscuirse en la trama del tejido urbano, a través de la valorización de sus horizontes interiores: linderos de las arboledas y bosques, riberas fluviales, o por la creación de pasillos verdes y "balcones" destinados a abrir "nuevos horizontes sobre la ciudad" recurriendo a lo vegetal, a través de la alianza con el agua", escribe Alain Fleischer ${ }^{22}$.

Esta presencia del paisaje dentro de la ciudad no debe limitarse a las instalaciones recreativas: parques, jardines, miradores y paseos; debe integrarse a la misma actividad económica, especialmente por el lugar otorgado a una agricultura urbana, que restablece una relación de proximidad entre habitantes de la ciudad y habitantes del campo. De una manera más general, recurrir al paisaje se revela como un medio de reanudar la comunicación, distendida por la práctica de la zonificación, entre las diversas actividades humanas: el hábitat y el trabajo, la industria y la agricultura, el comercio y la naturaleza. Uno de los proyectos radica en la creación de "paisajes multifuncionales", "donde encontramos sucesivamente el aspecto residencial, la retención de las aguas, la producción alimentaria, la conservación de la biodiversidad y la producción energética"23.

Espacio de transición, el paisaje es un vector privilegiado de estas conexiones que habría que multiplicar para subsanar la división y las separaciones que afectan a la región parisina. Uno de los proyectos promueve la imagen de una "metrópoli porosa", que "restablece las conexiones, facilita los intercambios, mezcla las poblaciones", y en cuyo seno "el paisaje produce vínculos" ${ }^{24}$. Debido a que el paisaje ofrece una visión de conjunto de la ciudad, puede ayudarnos a convivir mejor, a tejer de nuevo los vínculos sociales.

Es probable que ninguno de estos proyectos se lleve a cabo nunca, pero poseen el mérito de iniciar una nueva forma de concebir el desarrollo urbano, que puede inspirar realizaciones parciales, susceptibles de mejorar el entorno vital de los habitantes de la aglomeración parisina. Y el hecho de que varios equipos hayan ubicado en el centro de su reflexión y prospectiva la noción de paisaje prueba que esta se aplica tanto a las ciudades como al campo, a su porvenir así como a su pasado, y puede contribuir a transformar no solo nuestras formas de pensar, escribir y crear, sino también nuestro modo de vida, y quizás nuestro mundo ${ }^{25}$.

20 Esta noción parece poder aclarar de manera útil los problemas que plantea la gestión del espacio a escala del planeta. Al igual que nuestras economías y sociedades, nuestro espacio está en crisis. A la brecha creciente entre ricos y pobres corresponde una fractura espacial. El espacio contemporáneo está caracterizado, si seguimos el diagnóstico de Marc Augé, por la proliferación de los no lugares, lugares de tránsito o errancia, lugares de eyección o deyección ${ }^{26}$. La uniformización del planeta ya no deja subsistir más que escasos lugares preservados, lugares de elección, lugares destacados del turismo o reservas etnográficas.

21 Es posible que el aplanamiento de las diferencias locales en beneficio de un espacio indiferente se remonte a la revolución copernicana, que nos hizo pasar de un mundo cerrado, siempre considerado a partir de un lugar singular, al universo infinito. Esta revolución permitió la matematización del espacio, y el desarrollo de una técnica capaz de allanar todos los obstáculos que se oponen a la estandarización y la racionalización del hábitat, o de una técnica apta para superar las distancias, siendo prueba de ello la comunicación instantánea que se instaura, en la red mundial, entre "sitios" que ya no están situados en ninguna parte. 

liberación de las clausuras y de las inercias locales. La modernidad valoró este nomadismo planetario, pero este también llevó a excesos y encontró límites de los que hoy tenemos una conciencia más clara. La globalización está acompañada por una trivialización ilustrada por ejemplo en arquitectura por los estragos del "estilo internacional": circulamos, pero ya no hay nada para ver. Y esta pérdida de identidad engendra un reflejo identitario propicio al surgimiento de los nacionalismos y de los integrismos, que restauran las barreras y fronteras que creíamos abolidas.

Esta fractura espacial nos expone a un doble escollo: la uniformización creciente de un espacio universal pero vaciado de su sustancia, y la fetichización de lugares convertidos en los refugios de una diferencia que se afirma con tanta más agresividad cuanto que se siente amenazada. Para escapar a esta peligrosa alternativa entre el reino del no lugar y la reivindicación de lugares de elección que tienden a ser lugares de segregación, lugares del "no" al extranjero, el paisaje propone un modelo para concebir una tercera vía. Ofrece la imagen de un área de transición que permite conciliar el arraigo en un lugar y la llamada de una lejanía, la singularidad de un punto de vista y el diálogo con el otro. Conlleva en efecto un horizonte, que le da sus contornos y su fisionomía, pero que se articula también con el lugar lejano. Punto de paso entre lo local y lo global, reúne el apego al país y la apertura al mundo, concebida no como una globalización uniformadora, sino una "mundialidad" 27 que preserva la identidad necesaria para el intercambio de las diferencias ${ }^{28}$.

\section{NOTAS}

1. Con fecha de 1338, es obra de Ambrogio Lorenzetti y adorna las paredes del Palazzo Pubblico de Siena.

2. [Suburbio situado al norte de París.]

3. [La "Cité des 4000", en francés, es un barrio de La Courneuve. En esta traducción dejaremos el término "cité" en francés, puesto que corresponde a una realidad urbanística propia de Francia: este vocablo alude a barrios marginales de ciudades periféricas o suburbios, caracterizados por bloques de viviendas sociales y conjuntos de edificios muy altos, de diez pisos o más, construidos en los años sesenta para alojar a una población en aumento en las grandes ciudades, población muchas veces inmigrante y desfavorecida. Los "4000" del nombre de la "cité" se refieren originariamente a 4000 alojamientos.]

4. [De la tradicional región francesa Champaña (Champagne en francés), situada hacia el noreste.]

5. [Departamento francés situado al sudeste, en la región Provenza-Alpes-Costa Azul.]

6. [Campus universitario de la ciudad homónima, en la periferia noroeste de París.]

7. [El juego de palabras en francés solo puede ser traducido imperfectamente en español: "déprime" en el original significa tanto la expresión geométrica "de prima" (D') así como la abreviatura coloquial de "depresión", "depre".]

8. Véase más adelante, p. 91-103. [Michel Collot dedica en estas páginas un estudio sobre el tema en un capítulo titulado: "Horizon et structure d'horizon : entre Orient et Occident" ("Horizonte y estructura del horizonte: entre Oriente y Occidente").]

Cuadernos LIRICO, 18 | 2018 
9. Véase Bernard Lassus, Une poétique du paysage. Le démesurable, París, B. Lassus, 1976.

10. [El autor emplea aquí la expresión "grands ensembles", que equivale a "cité". Véase supra la nota explicativa a este respecto.]

11. Véase el libro de Christian Norberg-Schulz, Genius loci. Paysage, ambiance, architecture, Bruselas, Mardaga, 1981.

12. Christian Norberg-Schulz, L'Art du lieu. Architecture et paysage, permanence et mutations, París, Le Moniteur, “Architextes”, 1997, p. 59.

13. Ibidem, p. 38.

14. Aaron Betsky, Lignes d'horizon. L'architecture et son site, Londres, Thames and Hudson, 2002, p. 8 y 13.

15. Ibidem, p. 13.

16. Véase Le Grand Pari(s), catálogo de la exposición presentada en la Cité de l'architecture et du patrimoine [Ciudad de la arquitectura y del patrimonio], número especial de la revista AMC, París, Le Moniteur, 2009. [Nota 1: El título del catálogo -Le Grand Pari(s)- contiene un juego de palabras tipográfico intraducible: significa a la vez "el Gran París" (le Grand Paris: la ciudad de París y sus suburbios) y "la gran apuesta" ('le grand pari' en francés). Nota 2: La Ciudad de la arquitectura y del patrimonio, situada en el oeste de París, en el distrito 16, es el mayor centro de arquitectura del mundo.]

17. Véase el proyecto de la agencia Grumbach y asociados, llamado "Sena Metrópoli", in Le Grand Pari(s), op. cit., p. 123-144.

18. Este es el caso en el proyecto del taller Castro Denissof Casi, ibidem, p. 211-232.

19. Ibidem, p. 218.

20. Presentación del proyecto de LIN - Finn Geipel + Giulia Andi, "Grand Paris Métropole douce" ["Gran París Metrópoli suave"], en la exposición Le Grand Pari(s), ibidem.

21. Jean Nouvel, citado en Le Grand Pari(s), ibidem, p. 158.

22. Ibidem, p. 160.

23. LIN - Finn Geipel + Giulia Andi, ibidem, p. 205.

24. Presentación del proyecto del Studio 09 - Bernard Secchi y Paola Viganò, en la exposición "Le Grand Pari(s)".

25. Muchas realizaciones recientes de gran calidad han mostrado ya la posibilidad de hacer entrar la naturaleza en la ciudad para renovar su paisaje. Varias de ellas fueron presentadas en 2011 en la Ciudad de la arquitectura y del patrimonio en París, en la exposición "La Ville fertile. Vers une nature urbaine" ["La ciudad fértil. Hacia una naturaleza urbana"]. Véase La Ville fertile [ La ciudad fértil], número especial de Paysage Actualités [2011]). Con respecto al trabajo de los paisajistas, véanse más adelante p. 187-197. [Collot dedica en estas páginas un estudio sobre el tema en un capítulo titulado: "Le paysagiste, architecte et jardinier de l'horizon" ("El paisajista, arquitecto y jardinero del horizonte").]

26. Véase Marc Augé, Non-lieux. Introduction à une anthropologie de la surmodernité, París, Le Seuil, "La Librairie du XXe siècle", 1992.

27. [Cabe notar que en francés Collot hace un juego de palabras entre el término para "globalización" ("mondialisation") y la voz entrecomillada propuesta ("mondialité", utilizada por É. Glissant, véase la nota siguiente), que tiene la misma raíz en francés que el primero.]

28. Véase la reflexión desarrollada por Édouard Glissant en el marco de una Poétique de la relation (1990) que analizo en "L'ouverture au(x) monde(s)" ["La apertura al (a los) mundo(s)"], en Paysage et poésie, París, José Corti Éditions, 2005, p. 371-392. 


\section{AUTORES}

MICHEL COLLOT

Université París III, Sorbonne Nouvelle 